\title{
Heterogeneity among septic shock patients in a set of immunoregulatory markers
}

\author{
H. Janols • M. Wullt • C. Bergenfelz • S. Björnsson • \\ H. Lickei • S. Janciauskiene $\cdot$ K. Leandersson • \\ A. Bredberg
}

Received: 20 May 2013 / Accepted: 8 August 2013 / Published online: 29 August 2013

(C) The Author(s) 2013. This article is published with open access at Springerlink.com

\begin{abstract}
Immune activation is a regular feature of sepsis, but the incidence and nature of the ensuing inflammationresolving and immunosuppressive component is less well understood. In this study, we compared immunoregulatory markers on blood leukocytes from patients with Gramnegative or Gram-positive sepsis or septic shock, and compared this to blood from patients with severe virosis or healthy controls. To this end, blood from 32 patients with sepsis, including ten cases with shock, and 12 patients with severe virosis were analysed by flow cytometry for the expression levels of monocyte HLA-DR, CD11c, CD14 and CD40, and for frequencies of $\mathrm{CD}_{163}{ }^{+}$-suppressive monocytes, HLA$\mathrm{DR}^{+}$or $\mathrm{CD} 40^{+}$-activated $\mathrm{T}$ cells and Tregs. Plasma cytokine levels were analysed as a functional measurement. Signs of immunosuppression dominated in the septic shock and Grampositive sepsis groups, whereas monocyte activation was common in Gram-negative sepsis patients without shock.
\end{abstract}

Karin Leandersson and Anders Bredberg shared senior authorship.

H. Janols $\cdot$ M. Wullt

Department of Infectious Diseases, Skane University Hospital,

Lund University, 20502 Malmo, Sweden

C. Bergenfelz $\cdot K$. Leandersson $(\square)$

Center for Molecular Pathology, Skane University Hospital,

Lund University, 20502 Malmo, Sweden

e-mail: karin.leandersson@med.lu.se

S. Björnsson

Cytometry Laboratory and Department of Laboratory Medicine,

Skane University Hospital, Lund University, 20502 Malmo, Sweden

H. Lickei $\cdot$ S. Janciauskiene

Department of Pulmonology, Hannover Medical School,

30625 Hannover, Germany

A. Bredberg

Department of Medical Microbiology, Skane University Hospital, Lund University, 20502 Malmo, Sweden
However, the main finding was the large inter-individual variation of immune activation and immunosuppression, with no correlation to prognosis among the shock patients. The pronounced inter-individual variation in the analysed monocyte and lymphocyte markers forms a strong argument that, when immunomodulatory treatment is considered in a sepsis patient, it should be personalised and guided by a detailed immune status assessment.

\section{Abbreviations}

APC Allophycocyanin

CARS Compensatory anti-inflammatory response syndrome

EBV Epstein-Barr virus

FITC Fluorescein isothiocyanate

MFI Mean fluorescence intensity

PD-1 Programmed cell death protein 1

PE Phycoerythrin

PE-Cy7 PE-cyanine7

PRRs Pattern recognition receptors

SIRS Systemic inflammatory response syndrome

Tregs T regulatory cells

\section{Introduction}

The incidence of sepsis is increasing, and there is still a high mortality associated with severe sepsis [1-4]. A wide spectrum of host responses [4-6] contribute to the considerable clinical heterogeneity, as well as to the repeated failures of clinical trials with inflammatory modulators [7-9]. The presence of a prominent immune activation, with a "cytokine storm", and even a "genomic storm" as shown in response to low-dose bacterial endotoxin [10], can be a sine qua non 
sepsis factor, occurring early and acting anti-microbially for the benefit of the host. Recently, consequences of the administration of immunosuppressive therapy became the subject of much attention [11-14]. Nowadays, these approaches are considered to be a major cause of sepsis mortality.

It is a debated question whether or not signs suggesting immunosuppression can be viewed to form a state of compensatory anti-inflammatory response syndrome (CARS) or not $[8,9,11,14]$. A perplexing sign observed early and in most sepsis patients is lymphopenia, mediated at least in part by apoptosis [15]. Whether this lymphopenia should be regarded as part of a compensatory immunosuppression, thus contributing to organ dysfunction and opportunistic infections commonly seen in later stages of the disease, is unknown. Experimental studies performed in mice suggest that inhibition of the sepsis-induced lymphocyte apoptosis specifically increases survival [16]. It has also been shown that $\mathrm{T}$ lymphocytes repopulate their respective compartments after sepsis via tightly regulated mechanisms [17]. Neither is it known whether clinically significant immunosuppression is a common phenomenon, or only occurring in the most advanced patients, thus rarely indicating a need for immune-restoring therapy. The answers to such questions are important because they decide whether sepsis patients should be monitored with immune biomarkers, and whether there is a need to develop appropriate immunomodulating therapeutics.

In this study, we made an attempt to broadly document the incidence and nature of immune alterations in sepsis patients with different clinical severity and causative microorganisms (19 gram-negative and 13 gram-positive patients) and compared this to patients with generalised virosis or healthy controls. We report that a marked inter-individual variation among sepsis patients indicates that sepsis care may benefit from a personalised approach, including a detailed assessment of immune status.

\section{Materials and methods}

\section{Patients}

Samples from all of the sepsis and virosis patients were obtained within 4 days after admission to hospital. The majority of samples were taken within 2 days [Gram-positive sepsis patients (7/10) and Gram-negative sepsis patients (7/ 12)] and those taken later than 2 days were especially controlled to not bias the conclusions in our study. For shock patients, the samples were obtained within 2 days. All patients were prospectively included, to cover a spectrum of illness severity including shock, and to have several microbial causative agents represented. Swedish national guideline criteria for sepsis diagnosis were adhered to, being similar to those of Bone et al. [18]. Sepsis was, thus, defined as the presence of a suspected or microbiologically proven infection, together with a systemic inflammatory response syndrome (SIRS), with SIRS defined by at least two of the following parameters: hypothermia $\left(\leq 36{ }^{\circ} \mathrm{C}\right)$ or hyperthermia $\left(\geq 38^{\circ} \mathrm{C}\right)$; tachycardia ( $\geq 90 / \mathrm{min}$ ); tachypnoea ( $\geq 20$ breaths/min) and/or arterial $\mathrm{PCO}_{2} 32 \mathrm{mmHg}$ or lower and/or mechanical ventilation; and leukocytosis $(\geq 12,000 / \mu \mathrm{l})$ or leukopaenia $(\leq 4,000 / \mu \mathrm{l})$ and/or a left-shifted white blood cell differential count of $10 \%$ or higher. Septic shock was defined as sepsis-induced hypotension persisting despite adequate fluid administration. There were 19 patients with sepsis, three patients with severe sepsis and ten patients with septic shock (Table 1). Since the patients with severe sepsis were so few, we chose to define them in the group of sepsis but not septic shock. Standardised antibiotic treatment according to Malmö University Hospital's guidelines was given until the cultures were finalised. The following subjects, with the indicated microbial agents recovered by culture or diagnosed by polymerase chain reaction (PCR) (using Swedish national QC-approved methods) were included: septic shock ( $n=10,3$ females and 7 males), with blood culture isolate of Escherichia coli (4 patients), Klebsiella oxytoca (1 patient), Staphylococcus aureus (2 patients), Streptococcus pyogenes (1 patient), and in two patients, no microbiological agent was isolated from blood but with suspected Gram-positive (1 patient) and Gram-negative (1 patient) etiology (these patients responded quickly to either Gram-positive or Gram-negative antibiotic treatment and also had clear symptoms from either the urinary tract or the lungs); Gram-positive sepsis ( $n=10,3$ females and 7 males), with blood culture isolate of $S$. aureus (3 patients), S. pneumoniae (4 patients), anaerobic cocci (1 patient) and the 9th and 10th patients with a probable pneumococcus etiology; Gramnegative sepsis ( $n=12,8$ females and 4 males), with blood culture isolate of $E$. coli ( 3 patients), K. oxytoca (1 patient), Citrobacter koseri (1 patient) and another five patients with significant quantity of $E$. coli in urine (Table 1$)$. The virosis cases ( $n=11,8$ females and 3 males) were one influenza A, four influenza B, two influenza H1N1 (one coinfected with influenza A), one hepatitis A, one acute hepatitis B and two HSV2 patients. Healthy controls were also included $(n=13,9$ females and 4 males). Ethical permit was obtained from the local ethical committee at Lund University (Dnr 288/2007) and an informed consent was given from the participating patients or their relatives if the patient was not in a condition to provide an informed consent him/herself.

Blood clinical routine methods

Venous blood was drawn in EDTA tubes and the time between sample collection and analysis was less than $6 \mathrm{~h}$. The leukocyte concentration and differential count were determined using an LH750 machine (Beckman Coulter, Hialeah, FL, 
Table 1 Clinical characteristics of the sepsis patients $(n=32)$

\begin{tabular}{|c|c|c|c|c|}
\hline Parameters & $\begin{array}{l}\text { Septic shock } \\
(n=10)\end{array}$ & $\begin{array}{l}\text { Gram-positive } \\
(n=10)\end{array}$ & $\begin{array}{l}\text { Gram-negative } \\
(n=12)\end{array}$ & $\begin{array}{l}\text { Healthy } \\
\text { controls } \\
(n=13)\end{array}$ \\
\hline Age, median years (range) & $74(51-87)$ & $68.5(33-89)$ & $51(20-79)$ & $46(26-64)$ \\
\hline Males & 7 & 7 & 4 & 4 \\
\hline 28-day mortality & 3 & 1 & & \\
\hline \multicolumn{5}{|l|}{ Length of ICU stay } \\
\hline Days median (range) & $6(1-49)$ & 0 & 0 & $\mathrm{n} / \mathrm{a}$ \\
\hline \multicolumn{5}{|l|}{ Length of hospitalization } \\
\hline Days median (range) & $23(3-53)$ & $7(3-55)$ & $4(3-46)$ & $\mathrm{n} / \mathrm{a}$ \\
\hline \multicolumn{5}{|l|}{ Ventilation } \\
\hline Days median (range) & $6(0-49)$ & 0 & 0 & $\mathrm{n} / \mathrm{a}$ \\
\hline \multicolumn{5}{|l|}{ Nosocomial infection } \\
\hline Percentage (number) & $50(n=5)$ & 0 & 0 & $\mathrm{n} / \mathrm{a}$ \\
\hline \multicolumn{5}{|l|}{ WBC count at enrollment } \\
\hline Cells $\left(\times 10^{6}\right) /$ ml median (range) & $20(1.5-60.4)$ & $18(8.6-32.3)$ & $8.7(5.1-32.4)$ & $5.7(4.6-11)$ \\
\hline \multicolumn{5}{|l|}{ Lymphocyte count at enrollment } \\
\hline Cells $\left(\times 10^{6}\right) / \mathrm{ml}$ median (range) & $1(0.1-2.4)$ & $1(0.3-2.1)$ & $1.2(0.5-2.4)$ & $1.8(0.8-3.7)$ \\
\hline \multicolumn{5}{|l|}{ Comorbidities } \\
\hline Diabetes & 3 & 3 & 3 & $\mathrm{n} / \mathrm{a}$ \\
\hline Renal failure & 1 & 1 & 0 & $\mathrm{n} / \mathrm{a}$ \\
\hline Cardiovascular disease & 5 & 6 & 4 & $\mathrm{n} / \mathrm{a}$ \\
\hline Pulmonary disease & 6 & 3 & 0 & $\mathrm{n} / \mathrm{a}$ \\
\hline Metastatic cancer & 1 & 0 & 1 & $\mathrm{n} / \mathrm{a}$ \\
\hline \multicolumn{5}{|l|}{ Blood or urine culture finding } \\
\hline Escherichia coli & 4 & $\mathrm{n} / \mathrm{a}$ & 10 & $\mathrm{n} / \mathrm{a}$ \\
\hline Citrobacter koseri & 0 & $\mathrm{n} / \mathrm{a}$ & 1 & $\mathrm{n} / \mathrm{a}$ \\
\hline Staphylococcus aureus (1 TSSS+) & 2 & 3 & $\mathrm{n} / \mathrm{a}$ & $\mathrm{n} / \mathrm{a}$ \\
\hline Streptococcus pyogenes & 1 & 0 & $\mathrm{n} / \mathrm{a}$ & $\mathrm{n} / \mathrm{a}$ \\
\hline Klebsiella oxytoca & 1 & $\mathrm{n} / \mathrm{a}$ & 0 & $\mathrm{n} / \mathrm{a}$ \\
\hline Klebsiella pneumoniae & 0 & $\mathrm{n} / \mathrm{a}$ & 1 & $\mathrm{n} / \mathrm{a}$ \\
\hline Streptococcus pneumoniae & 0 & 4 & $\mathrm{n} / \mathrm{a}$ & $\mathrm{n} / \mathrm{a}$ \\
\hline Gram-positive anaerobic cocci & 0 & 1 & $\mathrm{n} / \mathrm{a}$ & $\mathrm{n} / \mathrm{a}$ \\
\hline No bacteria isolated from blood/urine & 2 & 2 & 0 & $\mathrm{n} / \mathrm{a}$ \\
\hline
\end{tabular}

USA) using Swedish national QC-approved clinical diagnostic methodology.

\section{PCR method for Tregs}

The analysis of $\mathrm{FOXP}^{+} \mathrm{T}$ regulatory cells (Tregs) was performed by DNA methylation of the FOXP3 CpG-rich gene promoter, as previously described [19]. A limited number of whole blood samples was available for this purpose.

\section{Flow cytometry}

In this study, we chose to use the following markers; CD3, a marker for all T cells; CD8, a marker for cytotoxic T cells; CD11c, expressed on and used as a marker for dendritic cells, monocytes, macrophages, neutrophils and some B cells; CD14, expressed on all monocytes; CD40, the receptor for $\mathrm{T}$ cell-CD40L expressed on antigen-presenting cells (APCs) and indicates the level of activation, but is also expressed on a small subpopulation of $\mathrm{CD}^{+}{ }^{+} \mathrm{T}$ cells [20]; CD163, a scavenger receptor expressed on monocytes and macrophages and often used to represent activated anti-inflammatory cells [21]; HLA-DR, the human major histocompatibility complex class II used as an activation marker on monocytes, but also as a marker of immune suppression when downregulated. HLADR can be expressed in activated T cells during severe infections [22].

The stainings were performed in a routine flow cytometry laboratory at Skåne University Hospital Malmö, with internal controls for isotype or staining variations. Whole blood 
$(50 \mu \mathrm{l})$ in each of the four tubes was incubated at room temperature with antibodies conjugated with the fluorochromes fluorescein isothiocyanate (FITC), phycoerythrin (PE), PE-Texas Red, allophycocyanin (APC) or Alexa-Fluor 647 and PE-cyanine7 (PE-Cy7) to permit up to five-colour analysis. The following antibodies were used: negative controls IgG1-PE or -FITC (clone 679.1Mc7; Beckman Coulter), CD45-ECD (clone J33; Beckman Coulter), CD3-APC, -PE, -ECD or -PCy5 (clone UCHT1; DakoCytomation), HLA-DRFITC (clone L243; Becton Dickinson), CD8-ECD (clone SFCI21Thy2D3; Beckman Coulter), CD14-PE-Cy7 (clone RM052; Beckman Coulter), CD40-PE (clone MAB89; Immunotech Beckman Coulter), CD64-FITC (clone 22; Immunotech Beckman Coulter), CD11c-PE (clone BU15; Beckman Coulter). The combination of antibodies used were as follows for each tube: negative control-FITC/negative control-PE/CD45-PE-Texas Red/CD3-APC, HLA-DRFITC/CD3-PE/CD8-PE-Texas Red/cholera toxin B-Alexa Fluor 647/CD14-PE-Cy7, HLA-DR-FITC/CD40-PE/CD3PE-Texas Red/cholera toxin B-Alexa Fluor 647/CD14-PECy7, CD64-FITC/CD11c-PE/CD45-PE-Texas Red/cholera toxin B-Alexa Fluor 647/CD14-PE-Cy7. The results for cholera toxin B and CD64 were scored only as part of a separate granulocyte study. Background autofluorescence and nonspecific binding of mouse Ig were monitored for two of the colours (FITC and PE) with isotypic non-specific mouse Ig, separately for lymphocytes and monocytes; the FITC-labelled non-specific mouse IgG was also used for setting the cut-off for HLA-DR-positive reaction in T cells. Monocytes were defined as $\mathrm{CD}^{-} \mathrm{CD} 14^{+}$cells with light-scattering typical for monocytes (when HLA-DR and CD40 were scored) or as $\mathrm{CD} 14^{+}$cells with $\mathrm{CD} 45$ intensity and light-scattering typical for monocytes (when CD11c was scored). The technical variation is low, as illustrated by the small variation observed for ten separate determinations of monocyte and lymphocyte HLA-DR (ten 50- $\mu$ l blood fractions from one patient were labelled with anti-HLA-DR-FITC; data not shown). A lyseno-wash protocol, or the automated Beckman Coulter TQprep machine, was used. In-house solutions for lysis and fixation were used. At least 1,000 events were analysed in an FC500 Beckman Coulter flow cytometer using both lasers. Acquisition and analysis were made using the CXP software (Beckman Coulter). Flow cytometry analysis of monocyte CD163 was performed as part of a separate study, on a subgroup of the shock patients $(n=6$; four with Grampositive and two with Gram-negative septic shock), using a FACSCalibur and the antibody conjugates CD14-FITC (clone M5E2), CD163-PE (clone GHI/61) and HLA-DR-APC (clone G46-6) from Becton Dickinson. An immune response index, intended to function as an indicator of overall immunoactivation or immunosuppression, was calculated for each patient. This index is based simply on those immune status parameters used in this study. It is, therefore, based on the results for three-monocyte (expression of HLA-DR, CD11c and CD40) and two-lymphocyte (frequency of activated $\mathrm{CD}^{+}$and $\mathrm{CD} 8^{+} \mathrm{T}$ cells) parameters. One point is awarded for a variation of one standard deviation from the mean of the healthy control result, up to a maximum of three standard deviations per parameter; for example, -0.8 SD for HLADR, -0.7 SD for CD11c, +3.1 SD for CD40, +5.6 SD for $\mathrm{CD}^{+} \mathrm{T}$ and $+6.5 \mathrm{SD}$ for $\mathrm{CD}^{+} \mathrm{T}$ give an index of +1.5 , indicating overall immunoactivation.

\section{Cytokine analysis}

Plasma was fresh-frozen at $-20^{\circ} \mathrm{C}$ and then analysed for IL-6, IL-1 $\beta$, IL-18, TNF- $\alpha$ and TIMP-1 by enzyme-linked immunosorbent assay (ELISA). The minimum detectable concentrations were: IL-6 $0.70 \mathrm{pg} / \mathrm{ml}, \mathrm{IL}-1 \beta 10 \mathrm{pg} / \mathrm{ml}$, IL-18 $12.5 \mathrm{pg} / \mathrm{ml}$, TNF- $\alpha 10 \mathrm{pg} / \mathrm{ml}$ and TIMP-1 $0.08 \mathrm{ng} / \mathrm{ml}$. All ELISA kits were from R\&D Systems.

Statistical analysis

The non-parametric Wilcoxon's two-sample rank test (the Mann-Whitney test) was used, and a $p$-value $<0.05$ was regarded as significant. Pearson's correlation coefficient was calculated in order to measure the correlation (linear dependence) between two variables. The calculation of the immune response index was based on the standard deviation because the healthy control data were considered to reflect a normal distribution.

\section{Results}

Markers of monocyte activation

Peripheral blood obtained from sepsis and virosis patients was analysed for leukocyte surface markers by flow cytometry. The results for the relative antigen density of four proteins (HLADR, CD11c, CD40 and CD14) known to be expressed by virtually all monocyte subsets, and with their level of density reflecting cellular activation status, are presented in Fig. 1a. This was performed as an attempt to illustrate the systemic innate immune response in these patients. The result is given as the mean fluorescence intensity (MFI), with the healthy controls' $(n=13)$ mean value set to 1.0 . The shock group consisted of both Gram-negative and Gram-positive cases, but was kept as one group because of the homogeneous pattern seen among the shock patients. A majority of the shock patients (9 out of 10 cases) $(p<0.001)$ and of the patients with Grampositive sepsis ( 7 out of 10$)(p<0.01)$ had a reduced MFI level of HLA-DR (i.e. an MFI lower than all of the healthy controls), whereas this was seen with only one case of Gram-negative sepsis (1 out of 12) and one case with virosis (1 out of 11). 
A

Monocyte immunophenotyping

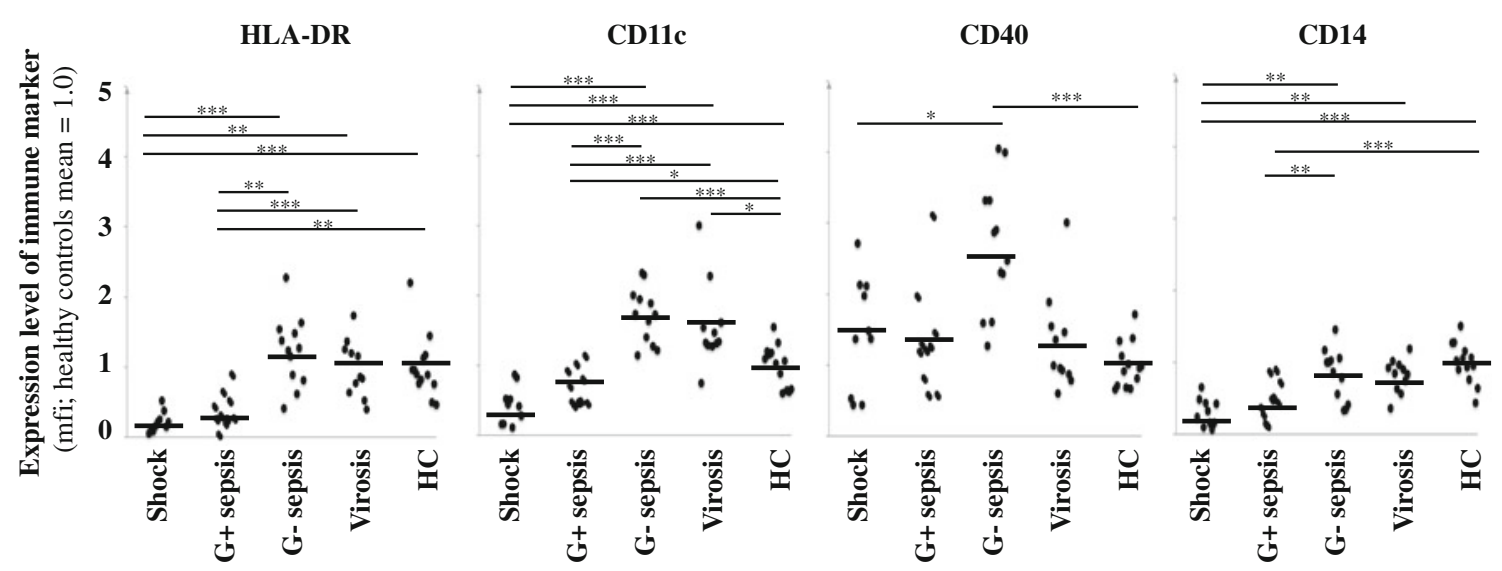

B

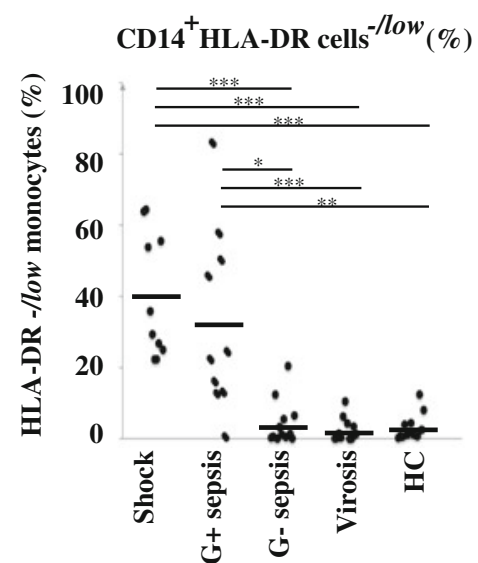

Fig. 1 Immunophenotyping of monocytes. a Peripheral blood was analysed by flow cytometry. The results show the mean fluorescence intensity (MFI) of the indicated markers expressed on monocytes. The thick black lines represent the mean for each group. Healthy controls (HC). $p$-values for the sepsis groups are shown. ${ }^{*} p<0.05,{ }^{* *} p<0.01$,

Monocyte HLA-DR was significantly lower in septic shock as compared with Gram-negative sepsis $(p<0.001)$. It has been proposed that HLA-DR ${ }^{- \text {low }}$ monocytes are anti-inflammatory cells that have been reprogrammed from conventional HLA$\mathrm{DR}^{+}$monocytes to elicit immunosuppressive signals [23]. In septic shock patients $(p<0.001)$ and in patients with Grampositive sepsis $(p<0.01)$, the size $(\%)$ of the HLA-DR ${ }^{-/ \text {low }}$ monocyte population was increased, while patients with Gram-negative sepsis and virosis had normal proportions of HLA-DR ${ }^{-/ \text {low }}$ monocytes (Fig. 1b).

For CD11c, there was a reduction in MFI levels on monocytes in patients with shock and Gram-positive sepsis as compared to healthy controls $(p<0.001$ and $p<0.05$, respectively). Noticeably, in the Gram-negative sepsis group, strongly CD11c $\mathrm{c}^{++}$monocytes were found in 8 of the 12 studied patients as compared to healthy controls $(p<0.001)$. Many cases from the virosis group also had a relatively high CD11c expression (Fig. 1a).
$* * * p<0.001$. b Size of the anti-inflammatory HLA-DR ${ }^{-/ \text {low }}$ monocyte population in peripheral blood ( $\%$ of gated monocytes). ${ }^{*} p<0.05,{ }^{*} p<$ $0.01, * * * p<0.001$. Shock patients $(n=10)$, Gram-positive sepsis patients $(n=10)$, Gram-negative sepsis patients $(n=12)$, virosis patients $(n=11)$ and $\mathrm{HC}(n=13)$

CD40 MFI levels varied in the septic shock group, where equally as many shock patients had monocytes with increased or decreased (4 out of 10 and 3 out of 10, respectively) levels of CD40 expression. The Gram-positive sepsis patients also showed a large variation in CD40 expression with increased or decreased levels of CD40 expression (2 out of 10), while a majority of Gram-negative sepsis patients $(p<0.001)$ presented with an increased level of CD40 (Fig. 1a).

The CD14 MFI levels were significantly reduced on monocytes in patients with shock and Gram-positive sepsis $(p<$ 0.001). Most of the Gram-negative sepsis patients and virosis patients had CD14 expression within the normal range (Fig. 1a).

\section{$\mathrm{CD} 63^{+}$monocytes increase in sepsis}

The fraction of monocytes with high expression of CD163, a monocyte subset considered to be anti-inflammatory, was 
elevated in all the analysed shock cases (with 6-88\% $\mathrm{CD}_{163}{ }^{++}$monocytes of all CD14 $4^{+}$gated monocytes, as compared with $0-1 \% \mathrm{CD} 163^{++}$monocytes in the healthy controls) (Fig. 2; $p<0.001$ ), indicating that the observed reduction of monocyte HLA-DR, CD11c and CD14 during shock is not merely a reflection of low vitality and general downregulation of monocyte protein levels.

\section{Marker (HLA-DR) of T lymphocyte activation}

As an attempt to illustrate the systemic adaptive immune response in septic patients, we next analysed the activation status of T cells using HLA-DR or CD40 expression, and the presence of Tregs (Fig. 3). The reason for the somewhat controversial choice of $\mathrm{T}$ cell activation markers was in an attempt to extract as much data as possible from already performed monocyte activation analyses. Although T lymphocyte HLA-DR, being an MHC class II molecule, does not directly participate in T cell activation, and seems not to be expressed in most $\mathrm{T}$ cells, its presence on the $\mathrm{T}$ cell surface is known to become detectable in response to virus infection. Moreover, we recently reported that the fraction of $\mathrm{T}$ cells with HLA-DR is typically increased for both the $\mathrm{CD}^{+} \mathrm{T}$ helper and $\mathrm{CD} 8^{+} \mathrm{T}$ cytotoxic subsets during various acute infections [22]. As expected, most virosis cases showed an increased proportion of HLA-DR ${ }^{+}$cells within the studied T cell populations $\left(p<0.05\right.$ for HLA-DR ${ }^{+} \mathrm{CD}^{+} \mathrm{T}$ cells and $p<0.05$ for the HLA-DR ${ }^{+} \mathrm{CD}^{+} \mathrm{CD}^{+} \mathrm{T}$ cells). Interestingly, four out of ten shock patients had a markedly increased proportion of HLA-DR ${ }^{+} \mathrm{CD}^{+} \mathrm{T}$ cells, while one had a reduced population (Fig. 3a). These same four cases also had an increased HLA-DR-positive fraction among the $\mathrm{CD} 8^{+} \mathrm{T}$ cell subgroup, while three out of ten of the shock cases had a clearly reduced fraction of HLA-DR ${ }^{+} \mathrm{CD} 8^{+} \mathrm{T}$ cells. In Gram-negative sepsis, there were several patients with a slightly increased fraction of HLA-DR ${ }^{+} \mathrm{CD}^{+}$T cells (5 out of 12 ), but, also, a decrease was seen in 7 out of 12 patients for both HLA-DR ${ }^{+}$ $\mathrm{CD}^{+} \mathrm{T}$ cells and HLA-DR ${ }^{+} \mathrm{CD}^{+} \mathrm{T}$ cells. In Gram-positive sepsis, there were several patients with an increased fraction of

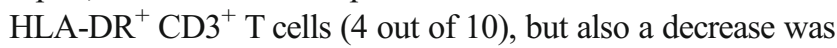
seen in two out of ten patients for both HLA-DR ${ }^{+} \mathrm{CD}^{+} \mathrm{T}$ cells and HLA-DR ${ }^{+} \mathrm{CD} 8^{+}$T cells. Overall, the Gram-positive sepsis cases showed a large inter-individual variation. There was no statistically significant difference between any of the sepsis groups and the healthy controls, because of the large interindividual variation among the patients (Fig. 3a).

CD40 is a co-receptor normally expressed on APCs. CD40 interacts with CD40L expressed on T cells and its expression is increased upon activation, leading to an increased $\mathrm{T}$ cell activation (CD40:CD40L interaction). Interestingly, also, a small population of $\mathrm{T}$ cells can express $\mathrm{CD} 40$ upon activation $[16,20]$. We, therefore, evaluated next whether CD40 expression on $\mathrm{CD}^{+} \mathrm{T}$ cells would increase upon sepsis or septic shock. As shown in Fig. 3b, the subpopulation of $\mathrm{CD} 40^{+}$ $\mathrm{CD}^{+} \mathrm{T}$ cells increased significantly in all patient subgroups with bacterial infections as compared to healthy controls, but not in virosis patients.

Tregs is a specific $\mathrm{T}$ cell subtype with immunosuppressive function. By analysing cytosine methylation of the $\mathrm{CpG}$-rich FOXP3 gene promoter (demethylation of this region is highly specific for Tregs, see [19]), we found a marked variation in Treg number in the six analysed shock patients, ranging from two cases with approximately half the frequency shown by the
Fig. 2 Frequency of a monocyte $\mathrm{CD} 163^{+}$cell type with immunosuppressive function. The fraction of monocytes with high CD163 expression $\left(\mathrm{CD} 163^{++}\right)$was determined by flow cytometry using peripheral blood from six patients with septic shock and ten healthy controls. The dot plots are gated on $\mathrm{CD} 14^{+}$monocytes (for the gates, see the left dot plots). The demographics did not differ significantly compared with all the patients with septic shock (according to mean age and sex ratio). The right dot plots (CD163 vs. HLA-DR) show a variable HLA-DR expression in the $\mathrm{CD} 163^{++}$monocyte population. $H C$ healthy controls. $* * * p<0.001$

\section{Monocyte CD16 $3^{++}$subset with suppressive function}

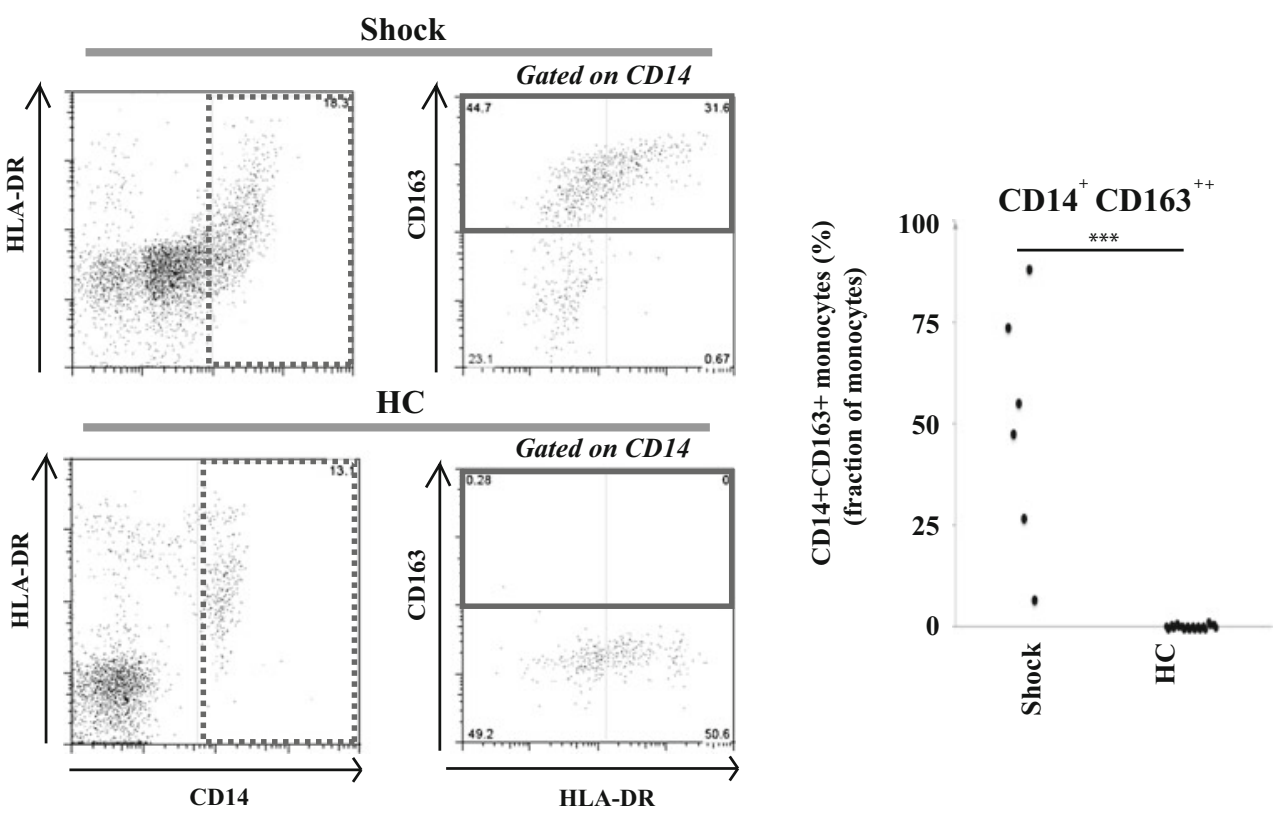


T lymphocyte immunophenotyping

A

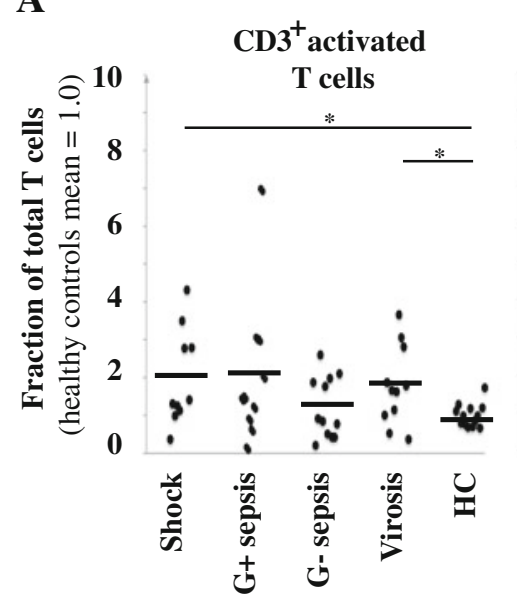

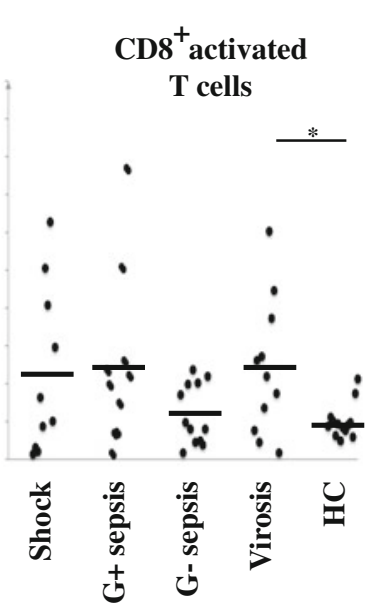

C
B

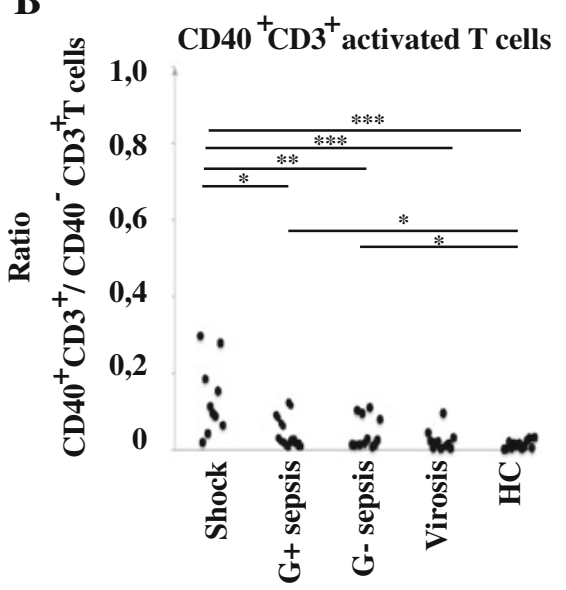

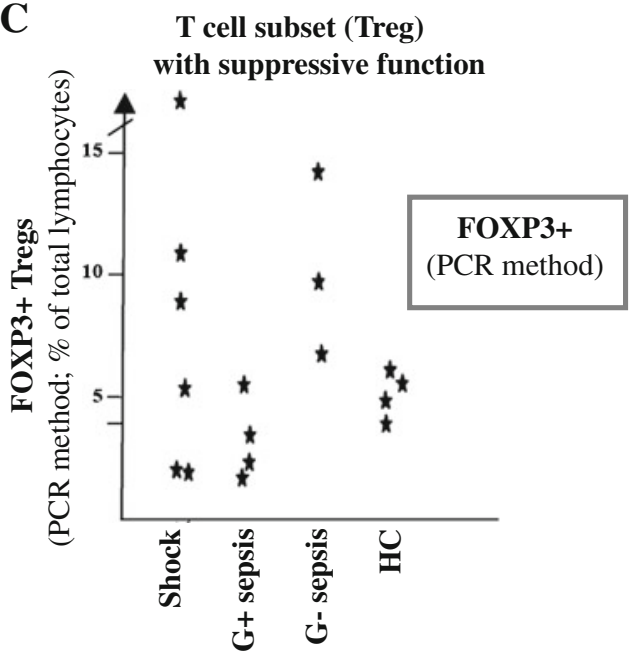

Fig. 3 Immunophenotyping of lymphocytes. a Peripheral blood was analysed by flow cytometry. The results show the fraction of all $\mathrm{T}$ cells with cell surface HLA-DR, and the result for healthy controls is set to 1.0. Healthy controls $(H C)$. $p$-values for virosis and shock are shown $(p<$ 0.05 ), and refer to a comparison with the healthy controls. The thick black lines represent the mean for each group. b The fraction of CD40-expressing $\mathrm{CD}^{+} \mathrm{T}$ cells was analysed. The values shown in the graph are the ratio of $\mathrm{CD}_{40}{ }^{+} \mathrm{CD}^{+} \mathrm{T}$ cells $(\%) / \mathrm{CD} 40^{-} \mathrm{CD}^{+} \mathrm{T}$ cells $(\%)$ for each

analysed healthy controls up to three times that of the highest of the controls (Fig. 3c). For Gram-positive sepsis (four patients were analysed), there was a lowered or normal Treg level; in contrast, patients with Gram-negative sepsis displayed an increased level, for all three cases analysed by PCR. In the virosis control group, there were only slight deviations from the normal Treg frequency (analysed with the DNA methylation method; results not shown).

Immunoreactivity patterns of individual patients

As mentioned above, CD40 is known to enhance T cell activation (CD40:CD40L interaction). To be able to determine whether strong monocyte expression of CD40 is accompanied patient. $H C$ healthy controls. ${ }^{*} p<0.05,{ }^{*} p<0.01,{ }^{* * *} p<0.001$. Shock patients $(n=10)$, Gram-positive sepsis patients $(n=10)$, Gram-negative sepsis patients $(n=12)$, virosis patients $(n=11)$ and HC $(n=13)$. c The frequency of Tregs was analysed by PCR analysis of DNA methylation of the FOXP3 gene promoter. Blood was from patients with septic shock $(n=6)$, Gram-positive sepsis without shock $(n=4)$, Gram-negative sepsis without shock $(n=3)$ and $\mathrm{HC}(n=4$ for PCR)

by a high fraction of HLA-DR-positive T cells, we analysed the individual patterns of relative monocyte CD40 MFI as compared to the proportion of $\mathrm{HLA}_{-}-\mathrm{DR}^{+} \mathrm{CD} 3^{+} \mathrm{CD} 8^{+} \mathrm{T}$ cells (Fig. 4a). There was no apparent correlation between monocyte CD40 expression and the frequency of $\mathrm{HLA}_{-} \mathrm{DR}^{+} \mathrm{CD}^{+}$ $\mathrm{CD}^{+} \mathrm{T}$ cells (or activated HLA-DR ${ }^{+} \mathrm{CD}^{+} \mathrm{T}$ cells; results not shown) in single individuals. The CD40 $\mathrm{MFI}^{\text {high }}$ sepsis patients (four with septic shock, nine with Gram-negative sepsis and two with Gram-positive sepsis) differed widely in the result for activated T cells, although the Gram-negative sepsis patient group showed a trend towards high monocyte CD40 MFI with few activated T cells.

The heterogeneity among the sepsis patients was high. The monocyte and lymphocyte results for two shock patients are 
A

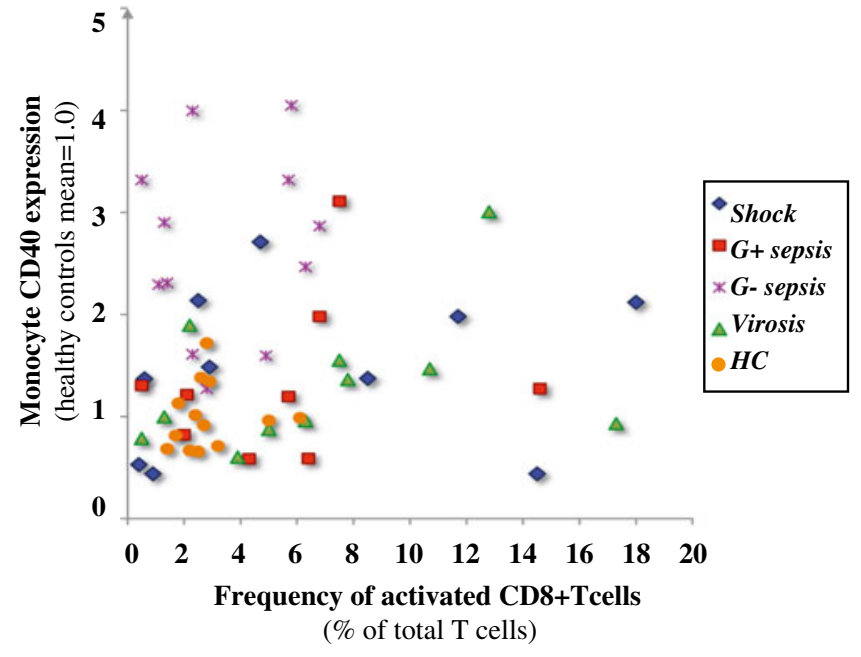

$\mathbf{B}$

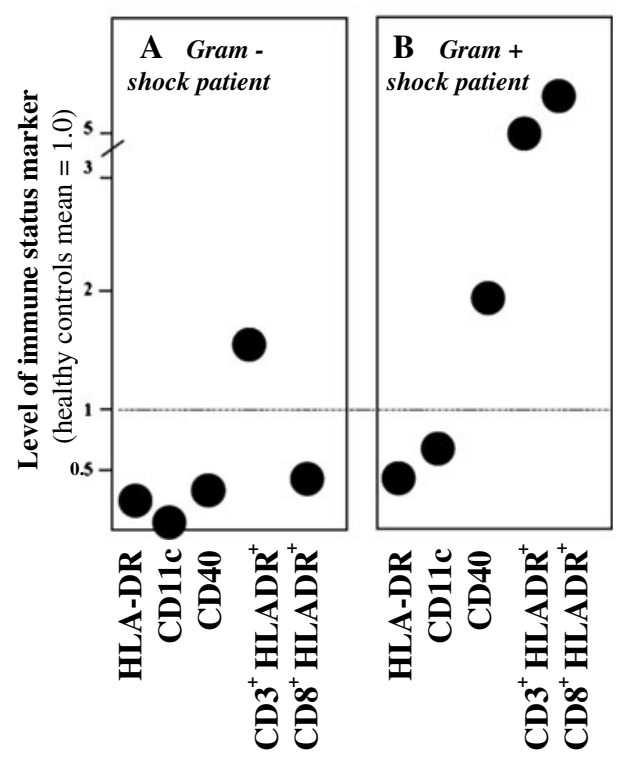

Fig. 4 a Monocyte CD40 expression in relation to activated $\mathrm{CD}^{+} \mathrm{T}$ cells. The results show monocyte CD40 intensity (MFI) and fraction of T cells being positive for HLA-DR. The CD40 expression level for healthy controls is set to 1.0. Each symbol denotes the result of one patient. Healthy controls $(H C)$. Shock patients $(n=10)$, Gram-positive sepsis patients $(n=10)$, Gram-negative sepsis patients $(n=12)$, virosis patients $(n=11)$ and $\mathrm{HC}(n=13)$. b Variation in immune response pattern between

shown in Fig. 4b. Importantly, an immunosuppressive pattern was never consistently found in any of the patient subgroups, but, rather, the opposite with mixed phenotypes within one patient and subgroup. Examples shown are one Gramnegative shock patient (subject A) displaying a dichotomy between the monocyte and lymphocyte immune responses and one Gram-positive shock patient (subject B) displaying an increased monocyte and lymphocyte immune activity, with a concurrent decreased HLA-DR and CD11c expression. Only seven of the 32 sepsis patients showed either a homogeneous pattern of either immunosuppression or immune activation.

In an attempt to provide an indicator of the net immune response for each patient, the results for three monocyte and two $\mathrm{T}$ cell parameters were used to calculate an immune response index (see "Materials and methods"). For the shock and the Gram-positive sepsis groups, the majority of the subjects shows an index suggesting a relatively normal index as compared to healthy controls, whereas all of the Gramnegative patients display a positive index indicating immunoactivation (Fig. 5). Also among the non-surviving shock individuals, there is variation: two cases with a positive index and two cases with a negative index. Negative values suggesting immunosuppression were seen for samples taken before day 1 as well as after 4 days, indicating no correlation with sepsis duration. No gender differences in any of the cell surface markers were detected. individual patients. The monocyte and lymphocyte results for two patients are shown, with each panel representing one subject. The dotted line is the mean of the healthy controls. HLA-DR, CD11c and CD40 show monocyte expression level; $\mathrm{CD}^{+} \mathrm{HLADR}^{+}$indicates the frequency of activated $\mathrm{CD}^{+} \mathrm{T}$ cells; $\mathrm{CD}^{+} \mathrm{HLADR}^{+}$indicates the frequency of activated $\mathrm{CD}^{+} \mathrm{T}$ cells

\section{Cytokines}

A majority of the patients and all of the healthy controls were analysed for plasma cytokine levels. Plasma IL-6 is produced mainly by activated monocytes/macrophages and considered to be a pro-inflammatory cytokine. Anti-inflammatory effects of this cytokine have also been proposed [20]. Significantly elevated levels $(p<0.05)$ of plasma IL- 6 was seen in patients with septic shock and in the Gram-positive sepsis group as compared to healthy controls (Fig. 6). One healthy control had high levels of IL-6, with otherwise normal values of all other analysed markers, but the reason for this is unknown. A markedly elevated level of IL-18 was seen in the Gram-positive sepsis group as compared to healthy controls $(p<0.01)$, but only to a moderate extent in the shock group. TIMP-1 is a metalloproteinase inhibitor produced by many cell types in response to IL-6 and other macrophage cytokines, with diverse functions possibly including those important for the resolution of inflammation [24]. TIMP-1 was analysed instead of IL-10 due to previous experiences with large variations using IL-10. Subjects with an elevated level of TIMP-1 were mainly found in the Gram-negative sepsis and septic shock group $(p<0.001)$ (Fig. 6). High levels of IL-1 $\beta$ and TNF alpha were seen in a few healthy controls as well as patients, but with no difference between the diagnostic groups (results not shown). 
Fig. 5 An index illustrating the net immune response of each patient. An immune response index is calculated, using the results for three monocyte (HLA-DR, CD11c and CD40) and two lymphocyte (activated $\mathrm{CD}^{+}$and $\mathrm{CD} 8^{+} \mathrm{T}$ cells, respectively) markers (see "Materials and methods" for details). A negative value (below the dotted line) suggests immunosuppression. The index is related to sepsis duration. Each symbol represents one patient sample and crossed symbols denote patients not surviving

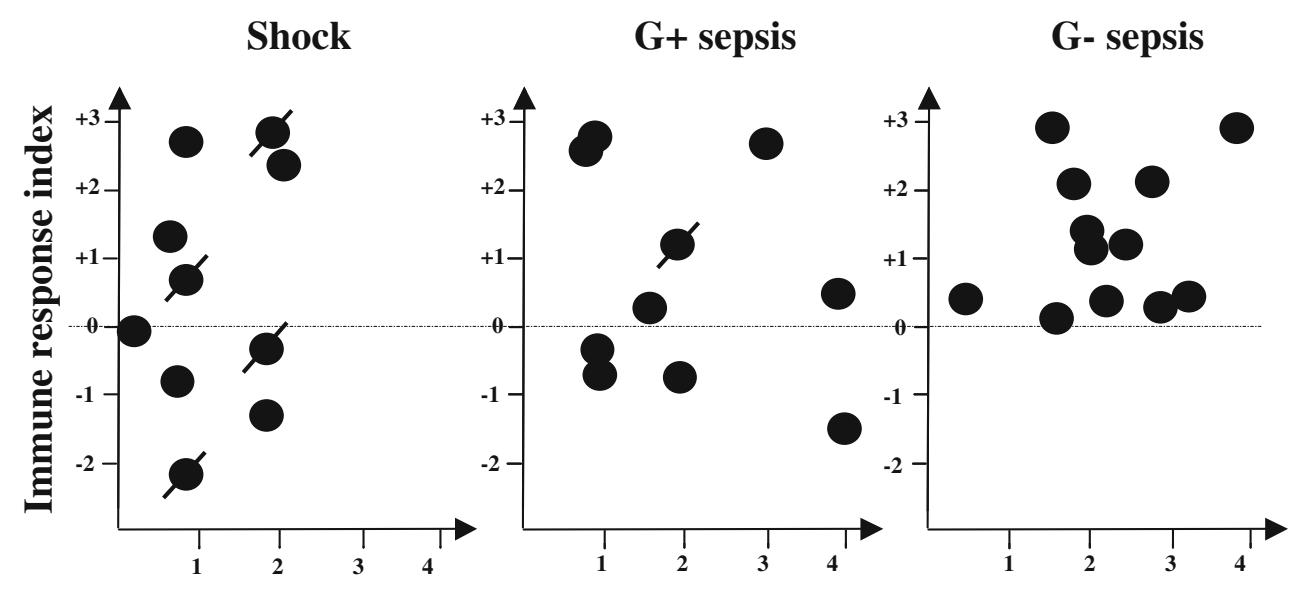

Sepsis duration (days from hospital admission to sample date)

\section{Discussion}

Sepsis is considered to be a complex disorder, and it has been suggested that it is probably too heterogeneous to treat as one disease [4]. One obvious reason is the variety of eliciting microbial agents carrying distinct sets of pathogenic factors. Many host factors influence the clinical picture, such as genetic determinants and co-morbidities influencing immune status. There can be variation even within the individual patient, as exemplified by an early appearing SIRS eliciting CARS $[4,11,25]$. Even though viruses are not conventionally judged to cause sepsis, we decided to use virosis as the control subgroup due to the systemic effects elicited by the immune response in these patients.

Monocyte cytokine production and the expression of surface markers are well known to become depressed in many sepsis patients [4-6, 11-13, 26, 27]. For instance, a weak production of pro-inflammatory cytokines by ex vivo-stimulated monocytes and a low level of cell surface CD14 expression were noted to correlate with sepsis severity [28]. However, a more recent report also demonstrated a high level of immunosuppressive CD $163^{+}$monocytes already upon admission, and with no difference 7 days later, and with a lack of correlation between the frequency of this monocyte subset and clinical outcome, illustrating the complexity of the immune response in sepsis [29].

There was a wide variation in age between the study groups, with the oldest patients found in the group of septic shock. There is clear evidence that the incidence of sepsis increases slowly throughout most of adulthood, and the reasons for this is multifactoral [30]. It is generally agreed that the senescence in the immune system affects the adaptive immune response, which leads to major defects in the cell-mediated immunity and the humoral immune response, whereas the innate immune response is largely spared during life [31]. In this study, there were more males than females developing septic shock. It has been reported that the gender-related differences in the immune response could be part of the explanation for this behaviour [32]. A predominance of antiinflammatory mediators in women may have a protective effect in terms of developing severe sepsis and septic shock [32].

Most of our patients had one or several abnormal findings among monocytes and/or T lymphocytes deviating strongly from that of all the 13 healthy controls. Signs of immunosuppression were most evident in septic shock, regarding both the number of patients and the size of the alteration. However, this was sporadically seen also in all the other diagnostic groups studied, including the non-septical virosis group. Indeed, it should be noted that the levels of antigen cell surface expression are overlapping in a lot of cases. Therefore, conclusions regarding the immune status are impossible to draw. Still, we believe that our data indicate that the suppression of some immune functions most probably occurs in a majority of patients with sepsis, as well as in other severe infections. However, our main finding is the marked inter-individual variation regarding the number and intensity of signs of immunoreactivity. A major former study on immune changes during acute sepsis in humans suffers from a bias in terms of the fact that only samples from deceased patients were analysed [12]. The present study does not have that bias and suggests that, at least for the limited panel of markers used here, large inter-individual differences are evident. We emphasise the complexity of the homeostatic network operating in a sepsis patient that eventually decides whether or not the net result will be a functional clinically overt immunodeficiency $[33,34]$. These considerations are in line with a report appearing during the preparation of this manuscript [35].

Monocytes are known to be exceptionally plastic in phenotype and function, with a great capacity to adapt quickly to environmental stimuli $[23,36]$. Monocyte HLA-DR, CD11c, CD40 and CD14 are typically present on all monocytes, and they were selected because a high expression level has been reported to be a measure of immune activation. To the best of 


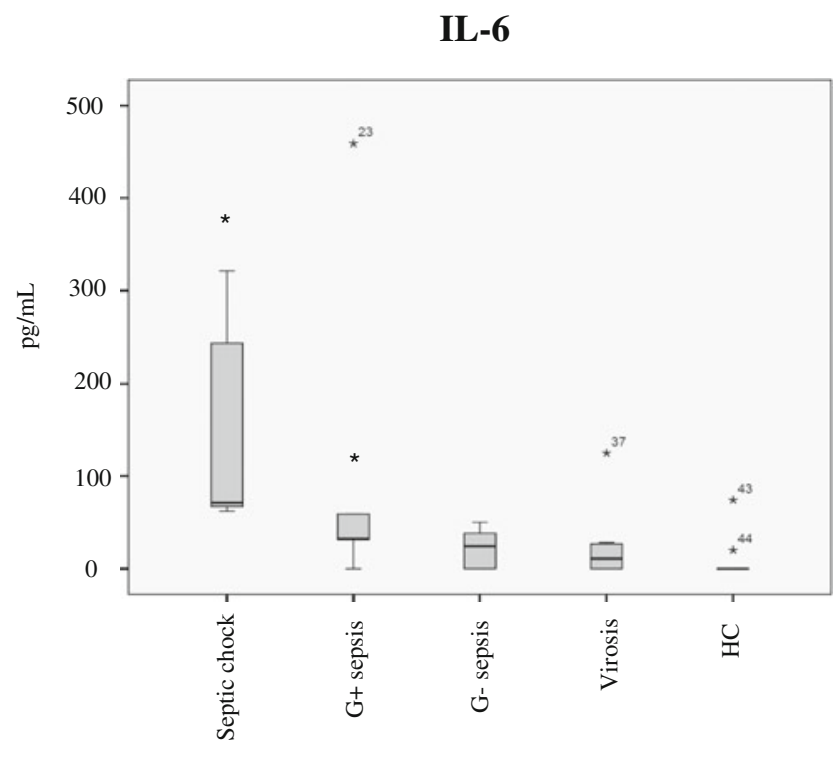

IL-18

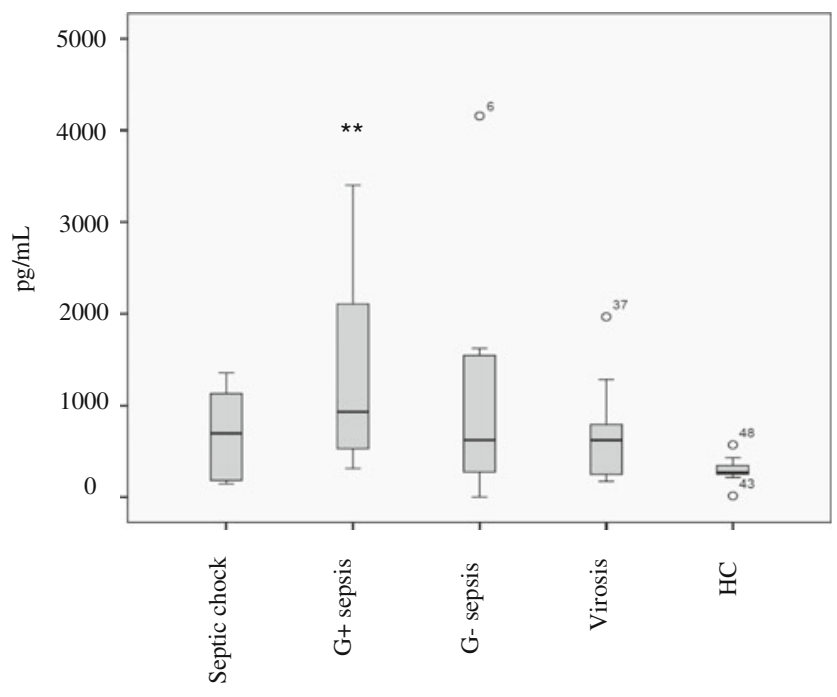

TIMP-1

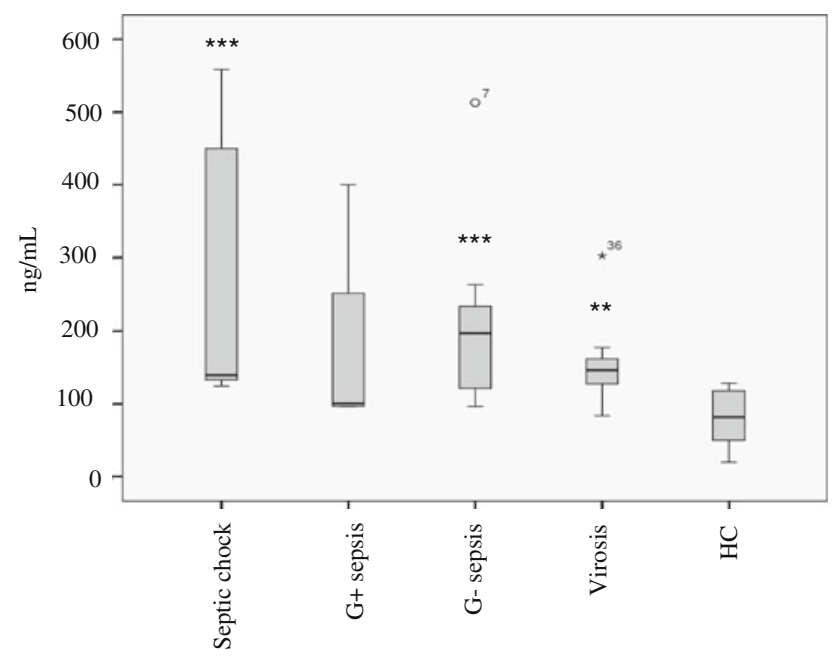

Fig. 6 Plasma cytokine concentrations. The box plots represent the variations in actual serum concentrations of IL-6, IL-18 and TIMP-1 in patient serum as compared to healthy controls $(H C) .{ }^{*} p<0.05,{ }^{* *} p<0.01$, $* * * p<0.001$

our knowledge, only for one of them, i.e. HLA-DR, has low expression been associated with immunosuppression [37]. However, we observe a clearly reduced cell surface intensity of HLA-DR, CD11c, and CD14 in comparison to the healthy control group in primarily septic shock and Gram-positive patients, in conjunction with a high level of immunosuppressive $\mathrm{CD} 163^{+}$monocytes. This also correlated to an increased proportion of the immunosuppressive HLA-DR ${ }^{-/ \text {low }}(\%)$ monocyte population, in the septic shock and Gram-positive patient groups. In general, it was interesting to note that, in sharp contrast to the Gram-positive patient group, patients with Gram-negative sepsis had a trend towards a proinflammatory activated monocyte pattern. Whether this difference is due to different immune response patterns being elicited by the various pathogens or is due to the clinical severity of the disease is worth discussing. Importantly however, monocyte CD40 expression showed a marked variation in all cases and sepsis groups, including shock, thus indicating an active CD40:CD40L immune activation also in patients with a typical immunosuppressive monocyte phenotype regarding HLA-DR, CD11c and CD14.

$\mathrm{T}$ cells are not counted as antigen-presenting cells, and, thus, are considered to lack HLA-DR; nevertheless, it is common knowledge that, upon activation, both $\mathrm{CD}^{+}$and $\mathrm{CD}^{+} \mathrm{T}$ cells express this molecule on their surface $[22,38]$. We considered HLA-DR to be a suitable $T$ cell activation marker for the present study, not only because of its strong fluorescence intensity, but also with regard to its in vivo expression (whereas, in our experience, the upregulation of e.g. CD25, i.e. the IL2R, can only rarely be documented in patients while being easily detected in $\mathrm{T}$ cells activated ex vivo) and to its kinetics, peaking relatively late (whereas e.g. CD69 appears already $2 \mathrm{~h}$ after stimulation). On average, none of the sepsis patient subgroups analysed had significantly altered proportions of activated T cells; however, especially in the shock group, there were cases with marked elevation or reduction, respectively, of activated $T$ cells. Interestingly, the alternative activation marker for T cells, CD40 [16, 39], was increased in all sepsis groups, suggesting further studies on this population in sepsis patients. Also, in the context of Tregs, this indicates that, although sepsis is a disease that, at the time points in this study (1-4 days after onset), would be expected to affect cells of the innate immune system primarily, we do actually see an activation of adaptive immunity.

Our observation of altered in vivo concentrations of cytokines in sepsis patients is in agreement with previous data [35], and provides evidence that our cellular results reflect functional derangements. Patient serum cytokine levels with 
respect to the type of pathogen might be worth analysing in more detail in the future, as would IL-10 levels in general. There are certainly additional factors to be considered when the relevance for the clinical situation of our findings are assessed, for example, whether a cellular change in the blood compartment results from the recruitment of cells from major reservoirs such as spleen or from an altered cellular state or even selective apoptosis of certain populations. A recent postmortem study on sepsis suggests that blood findings can mirror tissue status, because flow cytometric analysis of both spleen and lung cells showed the expansion of suppressor cell populations [12]. A critical issue is which immunosuppressive characteristics indicate that the patient is in a net state of immunosuppression conferring increased susceptibility to microorganisms, and, thus, should be treated accordingly. Whether an isolated finding of an increase in an immunosuppressive monocyte marker such as HLA-DR, CD163 or programmed cell death protein 1 (PD-1) [12, 40, 41] merit immunoactivating treatment is worth debating. The principal issue is: what amount of measurable phenotypic or functional cellular depression is needed in order for a clinically relevant immunodeficiency to occur. In conclusion, our findings of a pronounced inter-individual variation in the analysed monocyte and lymphocyte markers form a strong argument that, when immunomodulatory treatment is considered in a sepsis patient, it should be personalised and guided by a detailed immune status assessment.

\begin{abstract}
Acknowledgements We thank Eva Johansson, Annette Ingemansson and Mohibullah Hotak for performing the flow cytometry analysis with great care and skill. This study was supported by grants from the Swedish Society of Medicine, the Swedish Cancer Foundation, the Medical Research Council, the UMAS Hospital Funds, Gunnar Nilsson's Cancer Foundation, and Ollie and Elof Ericsson's Foundation, Kocks Foundation, Alfred Österlunds Foundation.
\end{abstract}

Conflict of interest The authors declare that they have no competing interests.

Open Access This article is distributed under the terms of the Creative Commons Attribution License which permits any use, distribution, and reproduction in any medium, provided the original author(s) and the source are credited.

\section{References}

1. Martin GS, Mannino DM, Eaton S, Moss M (2003) The epidemiology of sepsis in the United States from 1979 through 2000. N Engl J Med 348(16):1546-1554

2. Harrison DA, Welch CA, Eddleston JM (2006) The epidemiology of severe sepsis in England, Wales and Northern Ireland, 1996 to 2004: secondary analysis of a high quality clinical database, the ICNARC Case Mix Programme Database. Crit Care 10(2):R42

3. Melamed A, Sorvillo FJ (2009) The burden of sepsis-associated mortality in the United States from 1999 to 2005: an analysis of multiple-cause-of-death data. Crit Care 13(1):R28
4. Wiersinga WJ (2011) Current insights in sepsis: from pathogenesis to new treatment targets. Curr Opin Crit Care 17(5):480-486

5. Hotchkiss RS, Karl IE (2003) The pathophysiology and treatment of sepsis. N Engl J Med 348(2):138-150

6. Ulloa L, Tracey KJ (2005) The "cytokine profile": a code for sepsis. Trends Mol Med 11(2):56-63

7. Hotchkiss RS, Opal S (2010) Immunotherapy for sepsis - a new approach against an ancient foe. N Engl J Med 363(1):87-89

8. Angus DC (2011) The search for effective therapy for sepsis: back to the drawing board? JAMA 306(23):2614-2615

9. Wenzel RP, Edmond MB (2012) Septic shock — evaluating another failed treatment. N Engl J Med 366(22):2122-2124

10. Xiao W, Mindrinos MN, Seok J, Cuschieri J, Cuenca AG, Gao H et al (2011) A genomic storm in critically injured humans. J Exp Med 208(13):2581-2590

11. Ward PA (2011) Immunosuppression in sepsis. JAMA 306(23):26182619

12. Sinistro A, Almerighi C, Ciaprini C, Natoli S, Sussarello E, Di Fino S et al (2008) Downregulation of CD40 ligand response in monocytes from sepsis patients. Clin Vaccine Immunol 15(12):1851-1858

13. Skrupky LP, Kerby PW, Hotchkiss RS (2011) Advances in the management of sepsis and the understanding of key immunologic defects. Anesthesiology 115(6):1349-1362

14. Huttunen R, Aittoniemi J (2011) New concepts in the pathogenesis, diagnosis and treatment of bacteremia and sepsis. J Infect 63(6):407419

15. Hotchkiss RS, Swanson PE, Freeman BD, Tinsley KW, Cobb JP, Matuschak GM et al (1999) Apoptotic cell death in patients with sepsis, shock, and multiple organ dysfunction. Crit Care Med 27(7): 1230-1251

16. Schwulst SJ, Grayson MH, DiPasco PJ, Davis CG, Brahmbhatt TS, Ferguson TA et al (2006) Agonistic monoclonal antibody against CD40 receptor decreases lymphocyte apoptosis and improves survival in sepsis. J Immunol 177(1):557-565

17. Unsinger J, Kazama H, McDonough JS, Hotchkiss RS, Ferguson TA (2009) Differential lymphopenia-induced homeostatic proliferation for CD4+ and CD8+ T cells following septic injury. J Leukoc Biol 85(3):382-390

18. Bone RC, Balk RA, Cerra FB, Dellinger RP, Fein AM, Knaus WA et al (1992) Definitions for sepsis and organ failure and guidelines for the use of innovative therapies in sepsis. The ACCP/SCCM Consensus Conference Committee. American College of Chest Physicians/Society of Critical Care Medicine. Chest 101(6):1644-1655

19. Wieczorek G, Asemissen A, Model F, Turbachova I, Floess S, Liebenberg V et al (2009) Quantitative DNA methylation analysis of FOXP3 as a new method for counting regulatory $\mathrm{T}$ cells in peripheral blood and solid tissue. Cancer Res 69(2):599-608

20. Bourgeois C, Rocha B, Tanchot C (2002) A role for CD40 expression on CD8+ T cells in the generation of CD8+ T cell memory. Science 297(5589):2060-2063

21. Brunialti MK, Santos MC, Rigato O, Machado FR, Silva E, Salomao $\mathrm{R}$ (2012) Increased percentages of T helper cells producing IL-17 and monocytes expressing markers of alternative activation in patients with sepsis. PLoS One 7(5):e37393

22. Janols H, Bredberg A, Thuvesson I, Janciauskiene S, Grip O, Wullt M (2010) Lymphocyte and monocyte flow cytometry immunophenotyping as a diagnostic tool in uncharacteristic inflammatory disorders. BMC Infect Dis 10:205

23. Sica A, Mantovani A (2012) Macrophage plasticity and polarization: in vivo veritas. J Clin Invest 122(3):787-795

24. Moore CS, Crocker SJ (2012) An alternate perspective on the roles of TIMPs and MMPs in pathology. Am J Pathol 180(1):12-16

25. Barreiro LB, Tailleux L, Pai AA, Gicquel B, Marioni JC, Gilad Y (2012) Deciphering the genetic architecture of variation in the immune response to Mycobacterium tuberculosis infection. Proc Natl Acad Sci U S A 109(4):1204-1209 
26. Lin RY, Astiz ME, Saxon JC, Rackow EC (1993) Altered leukocyte immunophenotypes in septic shock. Studies of HLA-DR, CD11b, CD14, and IL-2R expression. Chest 104(3):847-853

27. Xu PB, Lou JS, Ren Y, Miao CH, Deng XM (2012) Gene expression profiling reveals the defining features of monocytes from septic patients with compensatory anti-inflammatory response syndrome. J Infect 65(5):380-391

28. Brunialti MK, Martins PS, Barbosa de Carvalho H, Machado FR, Barbosa LM, Salomao R (2006) TLR2, TLR4, CD14, CD11B, and $\mathrm{CD} 11 \mathrm{C}$ expressions on monocytes surface and cytokine production in patients with sepsis, severe sepsis, and septic shock. Shock 25(4): 351-357

29. Biswas SK, Lopez-Collazo E (2009) Endotoxin tolerance: new mechanisms, molecules and clinical significance. Trends Immunol 30(10):475-487, Research Support, Non-U.S. Gov't Review

30. Angus DC, Linde-Zwirble WT, Lidicker J, Clermont G, Carcillo J, Pinsky MR (2001) Epidemiology of severe sepsis in the United States: analysis of incidence, outcome, and associated costs of care. Crit Care Med 29(7):1303-1310

31. Opal SM, Girard TD, Ely EW (2005) The immunopathogenesis of sepsis in elderly patients. Clin Infect Dis 41(Suppl 7):S504-S512

32. Schröder J, Kahlke V, Staubach KH, Zabel P, Stüber F (1998) Gender differences in human sepsis. Arch Surg 133(11):1200-1205

33. Borovikova LV, Ivanova S, Zhang M, Yang H, Botchkina GI, Watkins LR et al (2000) Vagus nerve stimulation attenuates the systemic inflammatory response to endotoxin. Nature 405(6785): $458-462$
34. Serhan CN (2007) Resolution phase of inflammation: novel endogenous anti-inflammatory and proresolving lipid mediators and pathways. Annu Rev Immunol 25:101-137

35. Boomer JS, Shuherk-Shaffer J, Hotchkiss RS, Green JM (2012) A prospective analysis of lymphocyte phenotype and function over the course of acute sepsis. Crit Care 16(3):R112

36. Porta C, Riboldi E, Totaro MG, Strauss L, Sica A, Mantovani A (2011) Macrophages in cancer and infectious diseases: the 'good' and the 'bad'. Immunotherapy 3(10):1185-1202

37. Boomer JS, To K, Chang KC, Takasu O, Osborne DF, Walton AH et al (2011) Immunosuppression in patients who die of sepsis and multiple organ failure. JAMA 306(23):2594-2605

38. Amlot PL, Tahami F, Chinn D, Rawlings E (1996) Activation antigen expression on human T cells. I. Analysis by two-colour flow cytometry of umbilical cord blood, adult blood and lymphoid tissue. Clin Exp Immunol 105(1):176-182

39. Naka T, Nishimoto N, Kishimoto T (2002) The paradigm of IL-6: from basic science to medicine. Arthritis Res 4(Suppl 3):S233-S242

40. Brahmamdam $\mathrm{P}$, Inoue $\mathrm{S}$, Unsinger $\mathrm{J}$, Chang $\mathrm{KC}$, McDunn JE, Hotchkiss RS (2010) Delayed administration of anti-PD-1 antibody reverses immune dysfunction and improves survival during sepsis. $\mathrm{J}$ Leukoc Biol 88(2):233-240

41. Meisel C, Schefold JC, Pschowski R, Baumann T, Hetzger K, Gregor $\mathrm{J}$ et al (2009) Granulocyte-macrophage colony-stimulating factor to reverse sepsis-associated immunosuppression: a double-blind, randomized, placebo-controlled multicenter trial. Am J Respir Crit Care Med 180(7):640-648 